\title{
Charging Station Optimization Project Based on the Matrix Flexible Charging Reactor
}

\author{
Z.Y. Liang ${ }^{1,2}$, Weihua $\mathrm{Li}^{1,2}$, L.B. Wu ${ }^{1,2}$, Jiajun She ${ }^{1,2}$, Jiahan Chen ${ }^{1} \&$ Xucheng Guo ${ }^{1}$ \\ ${ }^{1}$ School of Electrical Engineering, Jinan University, Zhuhai, China \\ ${ }^{2}$ Institute of Rail Transportation, Jinan University, Zhuhai, China \\ Correspondence: Weihua Li, Institute of Rail Transportation \& School of Electrical Engineering, Jinan University, \\ No.206, Qianshan Road, Xiangzhou District, Zhuhai City, Guangdong Province, China.
}

Received: May 21, 2019 Accepted: July 11, $2019 \quad$ Online Published: July 21, 2019

doi:10.11114/set.v6i1.4282 URL: https://doi.org/10.11114/set.v6i1.4282

\begin{abstract}
In accordance with the Principle of "scientific planning, moderate advancement, rational layout, and classification implementation", the genetic algorithm based on real coding will be improved in this paper for the "Hard to Charge" problem of electric vehicles and urban bus replacement project. Aiming at minimum construction, operation and maintenance, network loss, queuing and other costs, a model is established and an innovative layout of electric bus charging facilities based on Matrix Flexible Charging Reactors is proposed to make full use of resources and improve the "Hard to Charge" situation. Taking Zhuhai as an example, by predicting the number of electric buses in Zhuhai in the planning year, the different locations and capacities of the bus charging stations with smaller average annual comprehensive cost in the regions are realized. And the comprehensive cost of the charging station with Matrix Flexible Charging Reactors as the construction subject is compared with the charging piles'. The analysis shows that this optimization proposal can better meet the future charging demand of urban electric buses, and proves that the charging station with Matrix Flexible Charging Reactors as the main subject of construction is more cost-effective. It provides new ideas for charging facilities planning in other cities, which is conducive to creating a healthier and more orderly environment for electric vehicle charging facilities industry.
\end{abstract}

Keywords: the matrix flexible charging reactor, charging facility, electric bus, minimum annual average planning cost, genetic algorithm, optimal charging station position coordinates

\section{Introduction}

China is the world's largest producer and seller of electric vehicles. As the country continues to promote the development and the advantages of new energy, the number of electric vehicles in China is increasing rapidly year by year, and the number of charging facilities is also increasing. However, in recent years, there are two major problems in the domestic charging facility operation market. One is that the growth scale of charging infrastructure is still far small than the growth scale of electric vehicles; the other is that problems such as insufficient capacity of urban power facilities and land resources have not been resolved at the source. The unreasonable planning of infrastructure facilities represents by charging piles and low utilization rate makes the charging configuration market low profit rate (Xu Fanting, 2018), hindering more funds into the charging market. These two major problems not only affect the progress of their own industries, but also lead to the slowdown in the development of electric vehicles, forming a vicious circle and hindering the development of new energy industries.

From the current research literature, most of the charging station planning focuses on the optimization of charging station layout based on charging piles. A two-step screening method and an improved original dual interior point method were proposed to solve the charging station model (Zhipeng Liu, Fushuan Wen, \&Gerard Ledwich, 2012). Jia Long et al. (2016) classify the charging demand according to the charging behavior of electric vehicle users, and establish a minimum cost planning based on the improved P-center positioning model. An activity-based assessment method is proposed to evaluate BEV feasibility for the heterogeneous traveling population in the real world driving context by Dong, J et al. (2014). A planning method considering the mutual complementation between different types of charging piles is proposed by Duan Qing et al. (2017). However, due to the current situation that the charging pile itself has many problems and the performance can not keep up with the development of the times, it is not scientific to 
manage to solve the problem of urban electric vehicle charging demand and construction cost only by optimizing the charging station planning proposals. Pan Yijun et al. (2018) compared the advantages and disadvantages of different charging technologies and station construction proposals. In terms of comprehensive operating costs in the whole life cycle, the flexible charging reactor model is far more effective. But there are scarce planning documents for optimizing the layout of charging facilities exclusively based on flexible charging reactors at present.

In view of this, combined with the urban bus replacement plan, this paper proposes an innovative layout of forward-looking electric bus charging facilities based on Matrix Flexible Charging Reactors, making full use of resources to improve the "Hard to Charge" situation. This paper improves the genetic algorithm based on real coding, and establish a model aiming at minimum construction, operation and maintenance, network loss, queuing and other costs. Zhuhai is taken as an example for detailed analysis and verification, and the comprehensive cost of the charging station with charging piles is compared.

\section{The Matrix Flexible Charging Reactor}

In December 2017, "electric vehicle charging reactor of flexible technical requirements" was formally carried out in Shenzhen, which provides a new mode of establishment, the Matrix Flexible Charging Reactor. The Matrix Flexible Charging Reactor integrates all or part of the charging modules of the electric vehicle charging station to form a power pool, and performs centralized monitoring and scheduling. According to the actual demand power of the electric vehicle during the charging process, the optimal number of charging modules is automatically matched. It is a highly integrated system which can quickly charge multiple electric vehicles. Matrix-type flexible charging reactors directly address the standard to solve the "charging anxiety" of charging time and charging power for new energy vehicles, which has many advantages. (Shenzhen Auto Electric Power Plant Co., Ltd., 2015).

- Flexible charging: Based on the power unit matrix control, the flexible charging stack monitors required power of the battery BMS in real time during the charging process, dynamically on demand allocates the number of charging modules to be input, and reassigns the exiting charging module to other charging ports, thereby improving the utilization of the charging module and the service capacity of the unit installed power.

- Power sharing: flexible charging reactor compatibility, through the full digital intelligent dispatch to meet the different power requirements of various vehicle charging, drastically improves the charging utilization and charging conversion efficiency.

- Upward compatibility: flexible charging reactor has higher adaptability, and can expand the corresponding charging module to meet the standard of high-power appliances. It can perfectly adapt to the rapid development of future car battery technology, and immensely extend the service life of charging equipment.

- Energy-saving and efficient: flexible charging reactor can ensure that the charging equipment can work in the optimal load rate range in order that the efficiency can reach $95 \%$ or more, not limited by the charging demand.

- Highly integrated: flexible charging reactor is highly integrated and easy to manage. At the same time, it is beneficial to save a lot of on-site installation time and commissioning time and shorten the construction period.

- Make the best use of it: Flexible charging reactor can combine the power grid, operators and owners together, and try to minimize the comprehensive construction cost, so that all three parties have good returns and their enthusiasm is improved.

In summary, the flexible charging reactor will change the charging mode from "one car to one car" to "a bunch of multiple cars", which will save the occupied land area and greatly reduces the need for power grid expansion. Better still, the centralized management will also make the charging station more secure. At the same time, the cost of charging facilities construction is reduced, which is quite conducive to popularizing new energy vehicles.

\section{Charging Station Optimization Planning Model}

\subsection{Urban Bus Replacement Project}

The optimal target of the Matrix Flexible Charging Reactor are the electric buses with the government management as the leading. Because it has the characteristics of its own bus station and fixed driving path, the distribution of charging facilities is mainly considering the charging demand of the buses.

In 2018, the Ministry of Transport proposed to promote the promotion of new energy vehicles as a key task, including the plan to transform conventional buses into new energy buses in various regions (MOT, 2018), namely the Urban Bus Replacement Project. Taking into account the bus electrification planning goals of most cities and the development of the next few years, future urban buses will basically be electric except for emergency spare vehicles. It can be seen that it is imperative to add supporting charging facilities, and the matrix flexible charging reactor will be a forward-looking choice. 


\subsection{Charging Demand Analysis}

The model for calculating the adding number of flexible charging reactors from the dimension of charge amount is:

Combining the configuration of most existing buses with the data on their nameplates, in the planning year, the daily average charging demand of electric buses in a planned charging station is multiplied by the average rated capacity of the battery, the average hundred volts rated voltage, the average percentage of remaining electricity, and the average daily effective charging time:

$$
W_{c}=(1-q) Q_{t} \cdot U_{100} \cdot T_{c}
$$

Where, the average rated capacity of the bus power battery is $Q_{t}$ (The unit is Ah). The average hundred volts rated voltage of the bus power battery is $U_{100}$. The average remaining power before each charge is $q$. The daily average effective charging time is $T_{\mathrm{c}}$.

The daily average effective charging time in a station can be calculated by the number of electric buses belonging to the station, the average number of times of charging, and the average charging time:

$$
T_{c}=k \cdot n \cdot T_{1}
$$

Where, the site has $n$ electric buses, each of which charges an average of $k$ times a day, and the average time spent on each charge is $T_{1}$.

Considering the actual situation, the average daily service capacity of a flexible charging reactor can be measured by effective work, that is, by multiplying the effective charging power by the daily effective service time:

$$
W_{d}=P_{d} \cdot T_{d}
$$

Where, the effective charging power of a flexible charging reactor is $P_{d}$. The daily average effective service time of a flexible charging reactor is $T_{\mathrm{d}}$.

The daily average effective service time of a flexible charging reactor can be calculated by the average daily service hours, the average number of service hours and the service time (in hours):

$$
T_{d}=m \cdot T_{2} \cdot H
$$

Where, the average number of hours of charging service per day is $\boldsymbol{H}$, and the number of services in one hour is $m$, and the average time of each charging service is $T_{2}$.

By comparing the average daily charging demand of electric buses in a planned charging station and the average daily service capacity of a flexible charging reactor, the number of flexible charging reactors that need to be built in each planned charging station during the planning year, can be obtained:

$$
N_{d}=\frac{W_{c}}{W_{d}}
$$

\subsection{Minimum Annual Average Planning Cost}

From the point of view of urban bus replacement, the main body of planning is the government or the Bus Group. Therefore, the optimization problem of charging facility location and capacity can be solved by the following model aiming at minimum construction, operation and maintenance, network loss, queuing and other costs. Liu Fei. (2015). $F$ is the minimum annual average planning cost of each charging station:

$$
\min F=\frac{r_{0}\left(1+r_{0}\right)^{Y_{e}}}{\left(1+r_{0}\right)^{Y_{e}}-1} C_{\text {inve }}+C_{\text {om }}+C_{\text {loss }}+C_{\text {wait }}
$$

Where, according to the equal annuity method, $r_{0}$ is the discount rate, and $Y_{e}$ is the service life of the equipment;

$C_{i n v e}$ is the total construction cost invested for each charging station, which generally consists of the construction site cost and the land cost:

$$
C_{\text {inve }}=C_{\text {con }}+C_{4}
$$

Where, $C_{\text {con }}$ is the construction site cost. $C_{4}$ is the land cost.

The construction site cost basically includes construction costs, equipment purchase costs and installation costs:

$$
C_{\text {con }}=C_{1}+C_{2}+C_{3}
$$

Where, $C_{1}$ is the construction cost. $C_{2}$ is the equipment purchase cost. $C_{3}$ is the installation cost. 
Construction and installation costs are usually proportional to equipment purchase costs, and the conversion factor is generally less than 1 :

$$
C_{1}+C_{3}=\beta C_{2}
$$

Where, $\beta$ is a conversion factor for the construction installation cost and equipment purchase cost.

The equipment purchase cost is multiplied by the unit price of the matrix flexible charging reactor and the number of flexible charging reactors required to be built:

$$
C_{2}=\mathrm{P}_{\mathrm{u}} \cdot N_{\mathrm{d}}
$$

Where, $P_{\mathrm{u}}$ is the unit price of purchasing a matrix type flexible charging reactor. $N_{\mathrm{d}}$ is the number of flexible charging reactors needed to be built.

The land cost is generally calculated by the price per square meter of the land and the size of the area to be built:

$$
C_{4}=\mathrm{P}_{\mathrm{g}} \cdot S
$$

Where, $P_{g}$ is the price per square meter of the land of the charging station, and $S$ is the area required for the construction site of a single planning charging station.

$C_{o m}$ is the annual average operating and maintenance cost in each charging station and is generally proportional to the cost of construction sites:

$$
C_{\text {om }}=\eta C_{\text {con }}
$$

Where, $\eta$ is the ratio factor between the operation and maintenance cost and the construction site cost (as a percentage of the initial investment).

$C_{\text {loss }}$ is the annual average net loss cost for each charging station, which can be calculated by the unit price of the electricity, the increase of the network loss, and the annual maximum utilization hours::

$$
C_{\text {loss }}=\alpha \Delta P_{\mathrm{i}} T_{\text {max }}
$$

Where, $\alpha$ is the price (including tax) of the unit charge purchased by the charging station, and its unit is $\mathrm{min} / \mathrm{kWh} . \Delta P_{\mathrm{i}}$ is the increase of network loss in the planning area after the planning charging station is introduced into the original grid. $T_{i \max }$ is the annual maximum load utilization hours of the charging station.

$C_{\text {wait }}$ is the annual average cost of bus queuing for charging in each charging station, usually consisting of the number of electric buses, the waiting cost factor of charging, the average waiting time per day, and the number of daily charging times:

$$
C_{\text {wait }}=365 \cdot \rho \cdot W_{x} \cdot k n
$$

Where, $\rho$ is the bus waiting cost factor for each charge, which is calculated by the bus driver's monthly income and working time through the wage method. The site has $n$ electric buses, and each of which charges an average of $k$ times a day.

$W_{x}$ is the daily average waiting time, which is obtained by the M/M/S queuing model integration. (Li, R., \& Su, H., 2011). And it is positively correlated with the daily average number of effective charging times and negatively correlated with the number of charging reactors in the station:

$$
W_{x}=\frac{\frac{\lambda^{N_{\mathrm{d}}}}{\left(\frac{60}{T_{\mathrm{c}}}\right)^{N_{\mathrm{d}}+1}}}{N_{\mathrm{d}} \cdot N_{\mathrm{d}} !}
$$

Where, $\lambda$ is the number of electric buses that need to be charged in the unit time.

\subsection{Restrictions}

Considering the realities, such as distribution network capacity and substation load, the charging station layout planning model also needs to add the following constraints:

(1) Restriction of the number of charging reactors in the charging station: subject to charging demand and constraints of 
the distribution network

$$
\frac{E}{R_{1}} \leq N_{d} \leq \frac{E}{R_{2}}
$$

Where, $N_{d}$ is the number of charging devices in the charging station; $R_{1}$ is the maximum service capacity of a single charging device in the charging station; $R_{2}$ is the minimum service capacity of a single charging device in the charging station; $E$ is the charging demand mentioned above.

(2) Bus charging station capacity constraints:

$$
A_{\mathrm{cmin}} \leq \sum A_{\mathrm{c}} \leq A_{\mathrm{cmax}}
$$

Where, $\sum A_{\mathrm{c}}$ is the total load of the substation that supplies the relevant area; $A_{\mathrm{cmin}}$ is the minimum load of the substation, and $A_{\text {cmax }}$ is the maximum load of the substation.

Through certain economic correlation analysis, combining the above various formulas, a mathematical model for the minimum cost of charging station planning can be constructed as follows:

$$
\begin{gathered}
\min F=\frac{r_{0}\left(1+r_{0}\right)^{Y_{e}}}{\left(1+r_{0}\right)^{Y_{e}}-1} C_{\text {inve }}+C_{\text {om }}+C_{\text {loss }}+C_{\text {wait }} \\
\text { s.t. }\left\{\begin{array}{l}
W_{c}=(1-q) Q_{t} \cdot U_{100} \cdot T_{c} \\
N_{d}=\frac{W_{c}}{W_{d}} \\
W_{d}=P_{d} \cdot T_{d} \\
\frac{E}{R_{1}} \leq N_{d} \leq \frac{E}{R_{2}} \\
A_{\mathrm{cmin}} \leq \sum A_{c} \leq A_{\mathrm{cmax}}
\end{array}\right.
\end{gathered}
$$

Because there are many variables in this model, such as the number of electric buses and the demand for charging stations, this unstructured complex problem is difficult to solve by traditional optimization algorithms. For this reason, the improved genetic algorithm is chosen to solve this problem.

\section{An Improved Adaptive Genetic Algorithm Based on Real Coding}

The genetic algorithm takes advantage of the ideas of biological evolution and genetics and is a mature artificial intelligence technology which has been applied to solve many practical problems, including the optimization problem of electric vehicle charging facility location and capacity (Dong J et al., 2014).

It is different from traditional optimization methods enumeration method or heuristic search algorithm, and it has the following characteristics: it can be used to solve complex problems unstructured, and it is robust and adaptable. The object it directly processes is the parameter encoding set, not the problem parameter itself. The searching process is not constrained by the optimization function that must be derivative and continuous. It can be easily parallelized, and also reduce costs. What's more, its basic idea is simple and has the standardized steps, which is convenient for specific use. Then the adaptive genetic algorithm greatly improves the convergence accuracy and speeds up the convergence by adaptively adjusting the genetic parameters.

In the establishment of charging station planning model by genetic algorithm, in order to convert the solution of planning problem into chromosomal gene form more accurately and improve the stability and efficiency of genetic operation, this paper has improved the adaptive genetic algorithm based on real coding. We use merge format (6) as the objective function, the penalty factor as constraint, and use the elite retention strategy and convergence formulas to strengthen the global search ability and achieve global optimality (He, J et al ., 2014). 


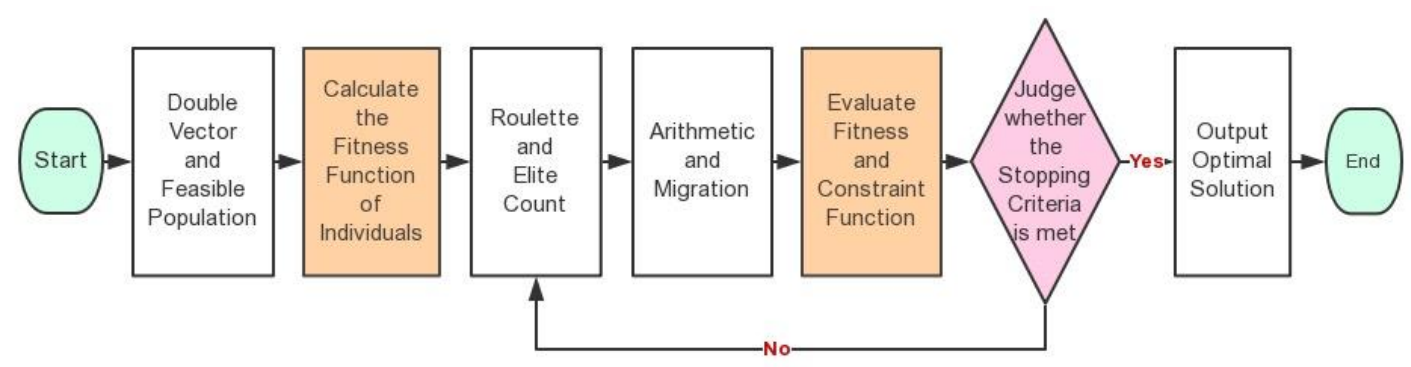

Figure 1. The flow chart of adaptive genetic algorithm based on real coding

\section{Instance Verification and Discussion}

This article will take the Xiangzhou District of Zhuhai City as an example to carry out the site selection and capacity planning of the new bus charging station and verify the correctness of the model.

\subsection{Reasons for Choosing Xiangzhou District of Zhuhai City as an Example}

This article selects Xiangzhou District of Zhuhai as an example mainly for two reasons: on one hand, China attaches great importance to the construction of "Guangdong, Hong Kong and Macao Bay Area", and the Hong Kong-Zhuhai-Macao Bridge will promote the efficient flow and configuration of innovative elements in Zhuhai, among which includes flow of people, logistics, capital flow and technology flow. With the constant increase of traffic volume and vehicle types, and the growing demand for charging infrastructure, Zhuhai needs to build the flexible charging reactors that can meet the need of different charging power and high utilization rate; on the other hand, by the end of 2018, Zhuhai has basically achieved comprehensive electrification of public transportation, and the progress rate counts among the best in the country. For this reason, new planning for charging facilities in Zhuhai is of urgent need. What's more, the Xiangzhou District is chosen because it is the central downtown area of Zhuhai.

\subsection{Analysis from the Investigation of the Charging Situation of Zhuhai Bus}

Our research team have visited many typical bus stations in the Xiangzhou area of Zhuhai by the means of field trips and interviews, and have learned more about the detailed situation of the Zhuhai bus charging station: confronted with Zhuhai's 2018 full-changing electric vehicle transformation plan, relevant industries have strived to adjusted to the change. But there are so many public transportation networks in Zhuhai that the beginning and end of the line must be built with charging facilities to meet the charging need of electric buses. Some long-distance lines also need to add hub stations in the middle. However, due to problems such as land resources shortage, some regions still fail to meet the demand for electric bus charging. Other common problems include more power consumption in the summer, delays caused by traffic jams, and the failure of charging pile standards or aging problems, make bus charging more time-consuming, which increases traffic pressure and makes it inconvenient for citizens to travel. We also observed that the city buses got in the ground bus station for charging are generally only a few minutes apart, so the charging demand can be described as "continuously flowing". In view of the comprehensive electrification and quantity of public transportation in the future, it is necessary to construct new charging facilities and carry out related urban planning.

\subsection{Forecast Data and Candidate Addresses}

The data of the number of buses in the calendar year can be obtained from the website of the National Bureau of Statistics and the Zhuhai Statistical Yearbook. And this article uses the Time Series Method to predict the amount of public transportation in the future. (Wang Xiaoling et al., 2017). From the ITDP China website, the proportion of pure electric buses can be obtained over the years. Similarly, except for the emergency standby energy vehicles and special conditions in some areas, it can be predicted that the national public transportation will basically achieve $100 \%$ electrification in 2025 . 


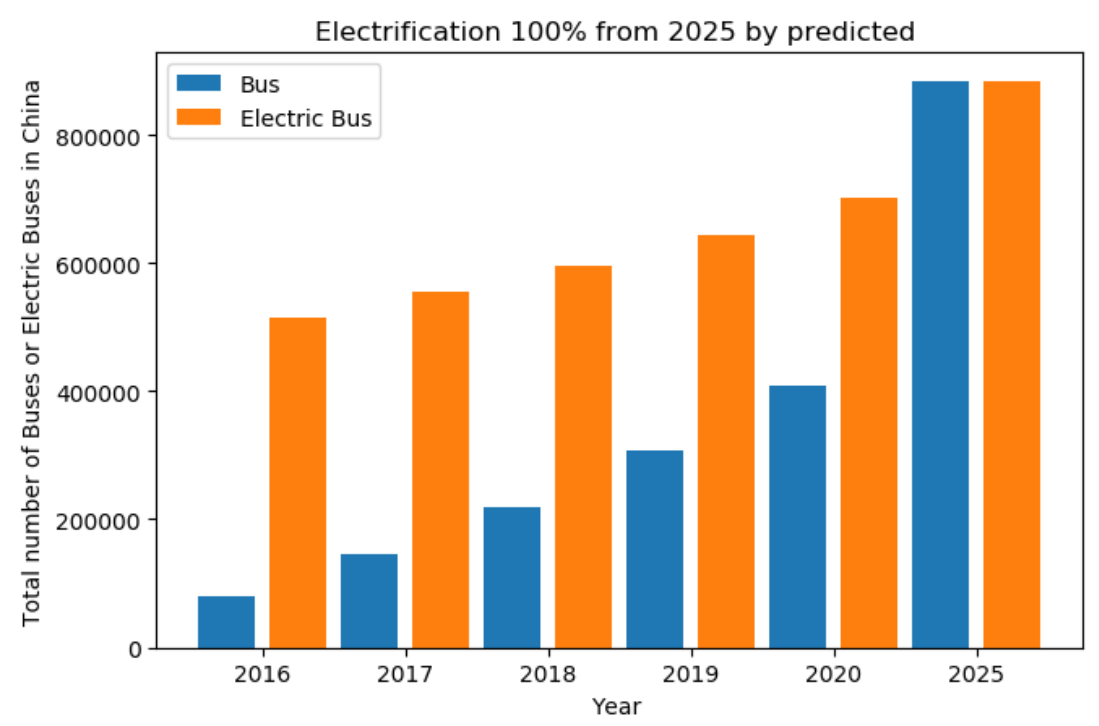

Figure 2. Total number forecast chart of Buses and Electric Buses

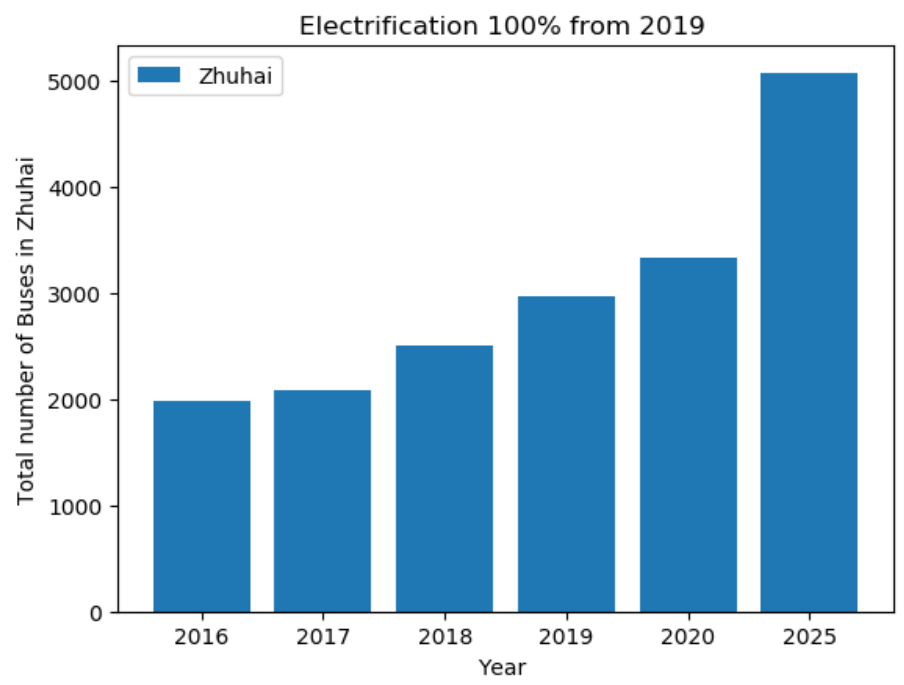

Figure 3. Total number forecast chart of Buses in Zhuhai (Electrification 100\%)

Xiangzhou District is the central downtown area of Zhuhai, which includes 8 streets, 6 towns, 145 communities and 7 administrative villages. According to the division street in the town of Xiangzhou District, this article will be divided into 9 bus charging communities, and considers the transportation convenience, land occupation area and power grid reconstruction cost and other factors, select an appropriate new charging station in each area site.

Assuming that by the planned year is 2025 , excluding emergency standby energy vehicles, the number of electric buses should account for $100 \%$ of the total number of buses. Considering the proportion of the population, the proportion of existing sites and the future development trend, the number of electric buses in each community of the planning year is calculated by predicting the total number of electric buses in Zhuhai. Then we got the Table 1 . 
Table 1. Site address and land price of candidate charging stations of each electric bus charging demand community in Xiangzhou District, Zhuhai

\begin{tabular}{ccccc}
\hline $\begin{array}{c}\text { Charging demand } \\
\text { communities }\end{array}$ & $\begin{array}{c}\text { The number of } \\
\text { electric buses in the } \\
\text { planning year }\end{array}$ & $\begin{array}{c}\text { Position coordinates of Candidate charging } \\
\text { stations }(\mathrm{km})\end{array}$ & $\begin{array}{c}\text { Land price } \\
\left(\text { Yuan } / \mathrm{m}^{2}\right)\end{array}$ \\
\hline Gongbei Street & 193 & $(3.016,3.304)$ & $(4.640,3.600)$ & 1030.0 \\
Wanzai Street & 42 & $(2.675,0.511)$ & $(2.738,0.000)$ & 711.0 \\
Qianshan Street & 340 & $(1.836,5.037)$ & $(1.922,7.155)$ & 927.0 \\
Cuixiang Street & 295 & $(5.647,9.752)$ & $(8.007,9.463)$ & 970.0 \\
Jida Street & 212 & $(7.725,6.745)$ & $(9.900,6.238)$ & 1018.0 \\
Shishan Street & 158 & $(6.329,9.031)$ & $(6.366,9.270)$ & 970.0 \\
Xiangwan Street & 90 & $(7.586,11.440)$ & $(8.404,13.275)$ & 619.5 \\
Meihua Street & 260 & $(3.720,8.932)$ & $(4.588,9.260)$ & 915.0 \\
Nanping Town & 110 & $(2.291,2.183)$ & $(0.000,3.548)$ & 1078 (Left), 706 (Right) \\
\hline
\end{tabular}

5.4 Parameters Selection

When calculating the model, the relevant parameters are set as follows: the average rated capacity of the bus power battery is $Q_{t}=170 \mathrm{Ah}$. The average hundred volts rated voltage of the bus power battery is $U_{100}=600 \mathrm{~V}$. The average remaining power before each charge is $q=60 \%$. Each bus charges a day as an average of $k=8$ times. The average time spent on each charge is $T_{1}=15 \mathrm{~min}$. The average number of hours of charging service per day is $H=15 \mathrm{~h}$, and the number of services in one hour is $m=7$, and the average time of each charging service is $T_{2}=5 \mathrm{~min} . \eta=0.1$ is the ratio factor between the operation and maintenance cost and the construction site cost. $r_{0}=0.1$ is the discount rate, and $Y_{e}=25$ year is the service life of the equipment. $\beta=0.15$ is the conversion factor for construction installation cost and equipment construction cost. The price (including tax) of the unit charge purchased by the charging station is $\alpha=95.1 \mathrm{fen} / \mathrm{kW} \cdot \mathrm{h}$. The bus waiting cost factor for each charge is $\rho=30 \mathrm{yuan} / \mathrm{h}$. The annual maximum load utilization hours of the charging station are $T_{i \max }=5000 \mathrm{~h}$ (idealized).

Considering the power factor and conversion efficiency, the effective charging power of the flexible charging reactor at a rated charging power of $800 \mathrm{~K}: P_{d}=800 x 0.99 x 0.95 \approx 752 \mathrm{~kW}$.

\subsection{Calculation Results}

A standard Matrix Flexible Charging Reactor can serve 16 electric vehicles at the same time, and the main body of the charging reactor only occupies 2 parking spaces. The single charging terminal takes up very little space, and can be added after the bus parking space. Therefore, the maximum number of charging terminals should not exceed 16. In all, no more than 16 parking spaces can be arranged for charging near each charging reactor.

We use equation (6) as the objective function, and equations (16) to (17) to perform preliminary search optimization for constraints, and use MATLAB to write an improved procedure for adaptive genetic algorithm. In this program, the operating parameters of the adaptive genetic algorithm are as follows: the population size is 50; the crossover probability is $0.4-0.9$; the mutation probability is $0.05-0.1$; and the maximum number of iterations is 100 . Finally, the optimization results and the location map of the model are obtained after the operation.

It is calculated that only one charging reactor and four charging terminals need to be installed in Wanzai Street. And only one charging reactor and eight charging terminals can be installed in Xiangwan Street to meet the regional charging demand. However, by retrofitting the current number of charging piles and the site, the regional charging demand can be also basically met, and the cost will be relatively lower. Therefore, it is not necessary for the two streets to plan according to our model, and that's the reason why their planning costs are not further calculated here. 
Table 2. Optimal address of bus charging station and its minimum annual average comprehensive planning cost

\begin{tabular}{cccccc}
\hline $\begin{array}{c}\text { The planning charging } \\
\text { area }\end{array}$ & $\begin{array}{c}\text { The } \\
\text { number of } \\
\text { charging } \\
\text { reactors }\end{array}$ & $\begin{array}{c}\text { The number of charging } \\
\text { terminals that each } \\
\text { reactor be equipped } \\
\text { with }\end{array}$ & $\begin{array}{c}\text { Site area } \\
\left(\mathrm{m}^{2}\right)\end{array}$ & $\begin{array}{c}\text { Optimal charging } \\
\text { station position } \\
\text { coordinates } \\
(\mathrm{km})\end{array}$ & $\begin{array}{c}\text { Minimum } \\
\text { annual average } \\
\text { comprehensive } \\
\text { cost (unit:10 } \\
\text { 000 Yuan) }\end{array}$ \\
\hline Gongbei Street & 2 & 10 & 3780 & $(3.016,3.304)$ & 166.96 \\
Qianshan Street & 2 & 15 & 5180 & $(1.836,5.037)$ & 214.25 \\
Cuixiang Street & 2 & 13 & 4810 & $(8.007,9.463)$ & 199.86 \\
Jida Street & 2 & 10 & 3780 & $(9.900,6.238)$ & 170.89 \\
Shishan Street & 1 & 15 & 3100 & $(6.329,9.031)$ & 102.71 \\
Meihua Street & 2 & 12 & 4090 & $(4.588,9.260)$ & 182.12 \\
Nanping Town & 1 & 10 & 2700 & $(0.000,3.548)$ & 106.50 \\
\hline
\end{tabular}

Table 3. Comparison of various costs required for charging stations with flexible charging reactors or charging piles as the main construction subject

\begin{tabular}{|c|c|c|c|c|c|c|c|c|}
\hline \multirow[t]{2}{*}{$\begin{array}{l}\text { The planning } \\
\text { charging area }\end{array}$} & \multicolumn{4}{|c|}{$\begin{array}{l}\text { Related costs of flexible charging reactors } \\
\text { (unit:10 000 Yuan) }\end{array}$} & \multicolumn{4}{|c|}{$\begin{array}{l}\text { Related costs of Charging piles } \\
\text { (unit:10 } 000 \text { Yuan) }\end{array}$} \\
\hline & $\begin{array}{l}\text { Construc } \\
\text { tion cost }\end{array}$ & $\begin{array}{c}\text { Annual } \\
\text { average } \\
\text { operation } \\
\text { and } \\
\text { maintenanc } \\
\text { e cost }\end{array}$ & $\begin{array}{c}\text { Annual } \\
\text { average } \\
\text { net loss } \\
\text { cost }\end{array}$ & $\begin{array}{c}\text { Annual } \\
\text { average } \\
\text { cost of } \\
\text { bus } \\
\text { queuing }\end{array}$ & $\begin{array}{l}\text { Construction } \\
\text { cost }\end{array}$ & $\begin{array}{c}\text { Annual } \\
\text { average } \\
\text { operation } \\
\text { and } \\
\text { maintenan } \\
\text { ce cost }\end{array}$ & $\begin{array}{c}\text { Annual } \\
\text { average } \\
\text { net loss } \\
\text { cost }\end{array}$ & $\begin{array}{c}\text { Annual } \\
\text { average } \\
\text { cost of } \\
\text { bus } \\
\text { queuing }\end{array}$ \\
\hline Gongbei Street & 909.34 & 52.00 & 20.21 & 4.03 & 1354.34 & 96.5 & 23.78 & 140.89 \\
\hline Qianshan Street & 1104.18 & 62.40 & 39.00 & 2.43 & 2180.17 & 170.00 & 45.89 & 248.20 \\
\hline Cuixiang Street & 1048.97 & 58.24 & 33.79 & 2.92 & 1941.57 & 147.50 & 39.75 & 215.35 \\
\hline Jida Street & 904.80 & 52.00 & 24.33 & 4.10 & 1444.86 & 106.00 & 28.63 & 154.76 \\
\hline Shishan Street & 612.70 & 31.20 & 20.62 & 8.36 & 1090.70 & 79.00 & 24.35 & 115.43 \\
\hline Meihua Street & 935.83 & 56.16 & 29.71 & 4.07 & 1674.24 & 130.00 & 34.95 & 189.80 \\
\hline Nanping Town & 450.62 & 26.00 & 28.48 & 7.93 & 740.62 & 55.00 & 33.52 & 80.30 \\
\hline
\end{tabular}

Due to different factors such as population, number of stations buses in different regions, the demands of bus charging and the size of sites required are accordingly different. Taking the land price, network loss and waiting cost into account, the differences of the annual comprehensive planning minimum costs are shown in Table 3.

Suppose that the unit price of the charging piles was 100 000, we calculated different costs for areas that meet the same demand by a car-to-pile ratio of 3:1. It can be seen from Table 4 that the total construction cost of the charging station with the charging piles as the construction subject is nearly twice as much as the flexible charging reactors'. From the comparison of the annual average operation and maintenance cost and the annual average net loss cost, the flexible charging reactor is obviously superior; and from the comparison of the annual average of bus queuing for charging, the cost saved by the flexible charging reactor is basically calculated in millions. It can be seen that the charging station with the flexible charging reactor as the main construction subject has better performance in terms of expense. In conclusion, it is highly recommended that major cities use flexible charging reactors as the main subject of construction when planning new bus charging stations. 


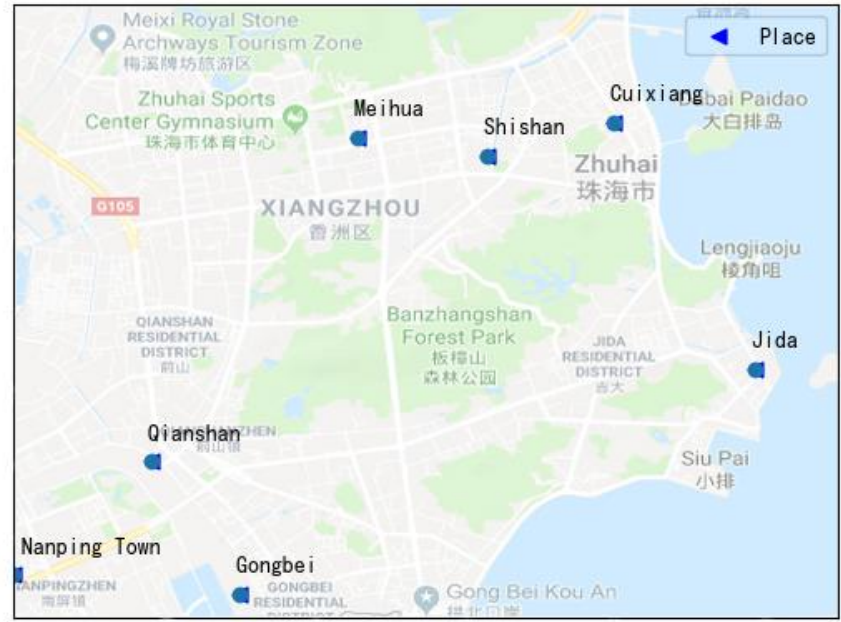

Figure 4. The optimization distribution result of charging station quasi-site in Zhuhai Xiangzhou District

By distributing the intensive charging stations around the charging demand cell, the optimization distribution result has avoided resource redundancy waste and has also met charging requirements of urban buses. However, there are still problems arising from the optimization results and the actual construction conditions. For example, the land may have other plans in progress. A better solution is to fine-tune on the basis of finding the right neighbors.

\section{Conclusion}

In view of the planning problem of electric bus charging station, combined with policy demand, taking Zhuhai bus as an example, this paper comprehensively takes urban construction plan, geographical factors and the cost of charging station construction, operation and maintenance, network loss, queuing into consideration, proactively propose an optimization planning model for electric bus charging stations based on a new type of charging equipment- the Matrix Flexible Charging Reactor. In the charge demand analysis, we not only searched for information from the official websites, but also conducted field research. By accessing multiple bus charging stations, we have obtained real and reliable data, which provides accurate verification for subsequent models and makes the model more specific and feasible. Based on the genetic algorithm, the optimal locations and capacities of the intensive bus charging stations are obtained after multiple iterations. Based on the results of the example, we can conclude that the model has certain forward-looking and scientific feasibility, and is suitable for medium and long-term bus charging station planning. Although this paper mainly analyzes the situation of electric buses in Zhuhai, the parameters in the model are universal, and thus have a certain guiding effect on the bus charging station planning in other cities. More practical considerations can be taken into account during the next stage, such as the recyclability of existing charging stations, the planning of being compatible with expansion and new construction, and the specific analysis of the different lengths of the bus lines.

\section{References}

Dong, J., Liu, C., \& Lin, Z. (2014). Charging infrastructure planning for promoting battery electric vehicles: An activity-based approach using multiday travel data. Transportation Research Part C: Emerging Technologies, 38, 44-55. https://doi.org/10.1016/j.trc.2013.11.001

Duan, Q., Sun, Y. L., Zhang, X. D., Huang, J. C., \& Li, H. W. (2017). Electric vehicle charging pile location and volume determination method. Power system protection and control, 45(12), 88-93. https://doi:10.7667/PSPC160958

He, J., Zhou, B., Feng, C., Jiao, H., \& Liu, J. (2012, December). Electric vehicle charging station planning based on multiple-population hybrid genetic algorithm. In 2012 International Conference on Control Engineering and Communication Technology (pp. 403-406). IEEE. https://doi.org/10.1109/ICCECT.2012.45

Jia, L., Hu, Z. C., \& Song, Y. H. (2016). An integrated planning of electric vehicle charging facilities for urban area considering different types of charging demands. Power System Technology, 40(9), 2579-2587. https://doi.org/10.13335/j.1000-3673.pst.2016.09.001

Li, R., \& Su, H. (2011). Optimal allocation of charging facilities for electric vehicles based on queuing theory. Dianli Xitong Zidonghua (Automation of Electric Power Systems), 35(14), 58-61. Retrieved from http://www.aepsinfo.com/aeps/ch/reader/view_abstract.aspx?file_no=201102126\&flag=1

Liu, F. (2015). Optimal Planning of Electric Vehicle Charging Station Layout Based on Genetic Algorithm. Power Science and Engineering, 31(8), 37-42. https://doi.org/10.3969/j.issn.1672-0792.2015.08.007 
Liu, Z., Wen, F., Xue, Y., \& Xin, J. (2012). Optimal siting and sizing of electric vehicle charging stations. Dianli Xitong Zidonghua (Automation of Electric Power Systems), 36(3), 54-59. https://doi:10.3969/j.issn.1672-3263.2016.12.170

MOT(Ministry of Transport of the People's Republic of China). (2018). Eight key tasks of the Ministry of Transport to tackle pollution prevention. Retrieved from http://www.mot.gov.cn/jiaotongyaowen/201806/t20180625_3036953.html

Pan, Y. J., Liang, L., Tang, M. G., \& Lu, L. J. (2018). Comparative analysis of electric vehicle charging technology 2.0 and 1.0. Information technology and information technology, 08, 162-168. https://doi.org/10.3969/j.issn.1672-9528.2018.08.051

Shenzhen Auto Electric Power Plant Co., Ltd. (2015). the Matrix Flexible Charging Reactor. Retrieved from http://www.atc-a.com/case_view.aspx?TypeId=50049\&Id=1190\&FId=t4:50049:4

Wang, X. L., Xie, Z. H., Tian, C. Y., \& Li, H. (2017). Research on predicting future car ownership based on time series method. Technological horizon, 01, 41-42. https://doi.org/10.19694/j.cnki.issn2095-2457.2017.01.022

$\mathrm{Xu}, \mathrm{F}$. T. (2018). Charging facilities should not become the bottleneck of electric vehicle development. Sinopec, 08, 25-28. https://doi:10.3969/j.issn.1005-457X.2018.08.006

\section{Copyrights}

Copyright for this article is retained by the author(s), with first publication rights granted to the journal.

This is an open-access article distributed under the terms and conditions of the Creative Commons Attribution license which permits unrestricted use, distribution, and reproduction in any medium, provided the original work is properly cited. 